\title{
RELATO DE EXPERIÊNCIA DE ACOLHIMENTOS EM UM CAPSi: IMPASSES E DESAFIOS
}

\section{Juliana Magrini Bernardi'; Bibiana Massem Homercher²; Mariéle Vargas Vieira³; Félix Miguel Nascimento Guazina ${ }^{4}$}

\section{RESUMO}

O presente estudo tem por objetivo refletir sobre a prática do acolhimento a partir do olhar de residentes em um Centro de Atenção Psicossocial Infanto Juvenil no interior do Rio Grande do Sul. Relato de experiência conjuntamente com revisão de literatura. Em decorrência disso, observou-se que a prática do acolhimento não está sendo realizada com o objetivo principal que é a construção de vínculo com o usuário, sendo construído o encaminhamento visando somente o olhar clínico, focado na doença, desconsiderando os aspectos sociais. Desse modo, o acolhimento sendo realizado como uma prática que propicia ao profissional reconhecer a situação do usuário e pensar processos interventivos considerando toda a sua realidade acaba por transformar as relações estabelecidas entre profissionais e usuários e destes com os serviços de saúde.

Palavras-chave: Acolhimento; Saúde Mental; Serviço de Saúde.

Eixo Temático: Atenção Integral e Promoção à Saúde.

\section{INTRODUÇÃO}

O acolhimento é um instrumento que auxilia os profissionais possibilitando construir vínculo e a confiança entre trabalhador e usuário. O ato de acolher não se limita apenas ao receber o usuário no serviço e sim proporcionar uma escuta qualificada, integrar o usuário ao serviço, fornecer informações visando sempre um

\footnotetext{
${ }^{1}$ Assistente Social Residente Multiprofissional em Saúde Mental, Universidade Franciscana (UFN). juuhmagrini@hotmail.com.

${ }^{2}$ Psicóloga Residente Multiprofissional em Saúde Mental, Universidade Franciscana (UFN). bibianamh@hotmail.com.

${ }^{3}$ Terapeuta Ocupacional Residente Multiprofissional em Saúde Mental da Universidade Franciscana (UFN). mariele1939@hotmail.com

${ }^{4}$ Doutor em Psicologia Social pela Pontifícia Universidade Católica do Rio Grande do Sul. Mestre em Psicologia Social pela Pontifícia Universidade Católica do Rio Grande do Sul. Docente da Universidade Franciscana (UFN). Coordenador da Residência Multiprofissional de Saúde Mental da UFN. guazina@gmail.com
} 
cuidado integral, "pressupõe a atitude, por parte dos profissionais e da equipe de saúde, de receber, escutar e tratar humanizadamente os usuários e suas demandas. É estabelecida, assim, uma relação de mútuo interesse, confiança e apoio entre profissionais e usuários" (SILVA JUNIOR e MASCARENHAS, 2006, p. 243).

O acolhimento apresenta-se como uma diretriz da Política Nacional de Humanização (HumanizaSUS) do Ministério da Saúde tendo como relevância ética, estética e política, sendo ética pois deve-se possuir um compromisso com a história do outro, suas tristezas, dificuldades e modos de viver. Estética, pois, possibilita estratégias para o enriquecimento da qualidade de vida e por fim política, pois, envolve o comprometimento do serviço para com aquele usuário que está de certo modo vulnerável e busca naquele espaço uma alternativa de melhora em sua vida (BRASIL, 2010).

Os Centros de Atenção Psicossociais (CAPS) foram serviços criados para atender a demanda de saúde mental, reorientando o modo de atenção à saúde, ofertando um espaço acolhedor, comunitário, direcionando o cuidado ao usuário de forma integral, abrangendo todos os aspectos de sua vida. Os CAPS contam também com uma equipe multiprofissional sob um olhar interdisciplinar, modificando dessa maneira, o modelo de saúde ofertado até meados do final de década de 1970, sendo um modelo de saúde mental totalmente hospitalocêntrico em que o atendimento era focado no saber psiquiátrico (NASI e SCHNEIDER, 2011).

O serviços de saúde mental possuem a Rede de Atenção Psicossocial (RAPS) como a ampliação e a articulação de pontos de atenção à saúde, vinculando os usuários aos serviços. A RAPS qualifica o atendimento ofertado ao usuário, promovendo ações intersetoriais, envolvendo e responsabilizando os profissionais, possibilitando a troca de saberes, experiências e campos de atuações em saúde diferentes (BRASIL,2014 ; SAMPAIO e JÚNIOR, 2021).

Os CAPS são divididos em diversas modalidades, entre elas, destaca-se no presente estudo o Centro de Atenção Psicossocial Infantil (CAPSi), sendo um espaço que oferece atendimento a crianças e adolescentes que apresentam algum sofrimento decorrente de transtorno mental grave e persistente. O CAPSi oferta 
diferentes atendimentos, entretanto, o atendimento inicial é o acolhimento do usuário e seu familiar (BRASIL, 2005).

O acolhimento é realizado quando o usuário chega ao serviço, sendo um facilitador para o acesso, tendo como orientador para a entrevista um formulário semiestruturado, aplicado para conhecer como foi o desenvolvimento da criança, como é constituído a relação familiar, o que está causando o sofrimento, território onde ela vive, sendo assim, requer dos profissionais uma escuta qualificada. A prática do acolhimento no CAPSi é desenvolvida por uma equipe multiprofissional de maneira interdisciplinar.

O trabalho multiprofissional na prática do acolhimento, torna-se fundamental, pois diferentes saberes se complementam e auxiliam para a construção do Projeto Terapêutico Singular (PTS). O PTS é um plano de ação terapêutico em que os profissionais compartilham saberes e pensam juntamente com o usuário e seu familiar qual será a melhor intervenção, salientando que o pensar em equipe soma e qualifica para o acompanhamento do caso (PINTO, et al, 2011).

Portanto, o acolhimento é o principal instrumento no serviço que contribui para a criação do vínculo entre usuário e profissional. Desse modo, o presente estudo relata a percepção de residentes sobre a prática do acolhimento em um Centro de Atenção Psicossocial Infanto Juvenil no interior do Rio Grande do Sul.

\section{METODOLOGIA}

O presente estudo caracteriza-se por relato de experiência conjuntamente com revisão de literatura. Trata-se de um estudo descritivo a partir das percepções de residentes de diferentes núcleos profissionais inseridas em um Programa de Residência Multiprofissional com ênfase em Saúde Mental em uma instituição privada.

Os acolhimentos foram realizadas em um Centro de Atenção Psicossocial Infantil localizado no interior do Rio Grande do Sul. Dessa forma, a pesquisa é de carater qualitativo, dentro de uma perspectiva crítica e reflexiva, conforme Minayo (2008) este método aplica-se a pesquisas para compreender a realidade através de diferentes percepções e interpretações. 


\section{RESULTADOS E DISCUSSÕES}

A prática do acolhimento requer que os profissionais do serviço de saúde mental sejam atenciosos e receptivos com o usuário, realizem a escuta de sua história de vida, queixas, angústias, tristezas, de uma maneira acolhedora (COELHO, 2010). O profissional que realiza essa prática, deve sempre orientar o usuário e sua família com muita responsabilidade, pois nem sempre o tratamento será no serviço que acolheu o indivíduo, devendo o profissional também encaminhálo para a rede.

No CAPS, de modo geral, o acolhimento é o primeiro contato presencial que o serviço tem com o(a) usuário(a). É onde acontece o início da construção dessa ponte entre a equipe e o indivíduo que procura auxílio nas questões relacionadas ao sofrimento psíquico, seja criança, adolescente e adulto. Por isso a responsabilidade de cada profissional é imensa, necessitando de uma conduta ética e sensível com a demanda que o outro traz.

Por isso, a escuta tem um papel muito importante no acolhimento inicial, é o instante de acolher a queixa, o relato, a história deste usuário, mesmo que isso pareça não interessar, de forma direta, o diagnóstico e tratamento. É preciso auxiliar a reconstruir, respeitando, os motivos que levaram o seu adoecimento e as relações que o indivíduo estabelece naquilo que ele sente com a sua vida (BRASIL, 2007).

O Projeto Terapêutico Singular (PTS) é um conjunto de proposições de prosseguimentos terapêuticos articulados, fruto da discussão coletiva entre a equipe interdisciplinar e o(a) usuário(a). A proposta é que seja realizado uma atenção integrada para o indivíduo, fazendo com que o(a) usuário(a) faça parte do seu próprio tratamento, sendo ativo, e não passivo frente ao atendimento psicossocial, sendo trabalhado com a singularidade de cada caso (BRASIL, 2007).

No CAPSi, que está sendo relatado neste artigo, realiza o primeiro contato presencial com os(as) usuários(as) através do acolhimento. É feito uma escuta com os familiares responsáveis da criança e do(a) adolescente, em geral, feito separadamente. Então alguns profissionais acolhem e dividem-se em dois grupos, 
aqueles que atendem a criança e/ou adolescente e aqueles que fazem a escuta do responsável familiar do menor.

É, então, preenchida a ficha de acolhimento. Nesta ficha é registrada os dados de documentos, o motivo da procura pelo serviço, informações sobre os familiares que residem na casa, história prévia de doenças orgânicas e psicogênicas, história do desenvolvimento da criança e do(a) adolescente, questões vinculadas a vulnerabilidade social desta família, entre outras informações.

Após isso, depois que os profissionais que acolherem o familiar e a criança ou adolescente, os profissionais discutem o caso com toda a equipe. Posterior a isso, voltam para conversar com a família para relatar o que pensaram sobre o caso e os possíveis encaminhamentos que serão realizados dentro do CAPSi, se o caso necessita de atendimentos psiquiátricos, psicológicos, fonoaudiológicos, de terapia ocupacional e do serviço social.

A questão é que o acolhimento e o Projeto Terapêutico Singular (PTS) nessa circunstância como é realizada neste CAPSi apresenta algumas fragilidades. Apesar de ser uma equipe multidisciplinar que faz o acolhimento, a forma como é conduzida pelos profissionais não é de uma construção juntamente com a família e com essa criança e/ou adolescente, e sim de uma lógica prescritiva, médica. Ou seja, ao invés de pensar em conjunto com a família o motivo desses encaminhamentos, o porquê do atendimento psiquiátrico, psicológico, entre outros, é apenas feito o encaminhamento.

O encaminhamento pode ser tanto para os atendimentos no CAPSi, caso o sujeito tenha o perfil para ser acompanhado ali, ou é enviado para a Rede de Atenção Psicossocial (RAPS) ou para a Rede de Saúde (RAS). O problema é que o acolhimento acaba sendo centrado nos possíveis encaminhamentos e direcionamentos desse usuário(a) do que, de fato, na escuta, na construção de algo em conjunto. Essa fragilidade acaba repercutindo um viés mais médico que psicossocial, repetindo, mesmo que implicitamente, um modelo higienista.

O CAPSi torna-se um ambulatório, uma clínica no sentido descrito da palavra, e não com práticas de atenção psicossocial e de clínica ampliada. Dentro do próprio CAPSi é criado listas de espera para atendimentos clínicos. O processo de 
ambulatorização dos CAPS cria um encapsulamento desses usuários(as), restringindo práticas produtivas de saúde mental, esquecendo-se da lógica para qual os CAPS foram construídos, para substituir hospitais psiquiátricos que tinham um regime não humanizado, e sim de isolamento desses sujeitos (LIMA e DIMENSTEIN, 2016).

Mesmo com as fragilidades apresentadas, a prática do acolhimento no serviço é fundamental para se pensar o fazer profissional, sendo que o trabalhador responsável busca promover o vínculo, apresentar o funcionamento do serviço e desenvolver mecanismos ou estratégias de resolução para os problemas que o usuário apresenta (MINÓIA e MINOZZO, 2015).

\section{CONCLUSÃO}

A prática do acolhimento é fundamental como atendimento inicial nos serviços, pois $\mathrm{o}$ ato de acolher envolve a escuta qualificada, conhecimento da realidade do usuário e criação de vinculo. Sendo um atendimento humanizado, tornando-se um facilitador do acesso ao usuário no sistema de saúde.

Percebe-se que o acolhimento também é essencial para a reorganização dos serviços de saúde, pois o usuário acaba por ser o centro do atendimento, fazendo com que os profissionais possuam um olhar ampliado abrangendo todos os aspectos de vida do usuário, qualificando assim os processos de trabalho. Sendo assim, percebeu-se que a lógica do CAPS de um atendimento humanizado, multiprofissional acaba por de certa maneira fragilizado, com um olhar focalizado na doença, ofertando ainda atendimentos ambulatorizados.

Desse modo, seria importante que existisse mais discussões com a equipe multiprofissional desse CAPSi a respeito do que é o acolhimento, repensando sua prática e destacando como ele é essencial para o início do vínculo e, consequentemente, a construção do Projeto Terapêutico Singular com o(a) usuário(a). Os profissionais da saúde são os agentes que compõem, constantemente, as práticas de saúde mental que necessitam estar em processos de reinvenção e reconstrução ou descontração, sendo o acolhimento uma delas. 


\section{QUFN}

\section{REFERÊNCIAS}

BRASIL. Ministério da Saúde. Atenção psicossocial a crianças e adolescentes no SUS: tecendo redes para garantir direitos. Brasília : Ministério da Saúde, 2014.

BRASIL, Ministério da Saúde. Secretaria de Atenção à Saúde. DAPE. Coordenação Geral de Saúde Mental. Reforma psiquiátrica e política de saúde mental no Brasil. Documento apresentado à Conferência Regional de Reforma dos Serviços de Saúde Mental: 15 anos depois de Caracas. OPAS. Brasília, 2005.

BRASIL. Acolhimento nas práticas de produção de saúde. Ministério da Saúde, Secretaria de Atenção à Saúde - 2. ed. 5. Reimp - Brasília: Editora do Ministério da Saúde, 2010.

BRASIL. Ministério da Saúde. Clínica Ampliada, Equipe de Referência e Projeto Terapêutico Singular. Brasília, Distrito Federal, 2007.

BRASIL. Politica Nacional de Humanização- PNH. : 1ª edição, Brasília - DF, 2013.

COELHO,V.F. Acolhimento em saúde mental na unidade básica: Uma revisão teórica. Monografia: especialização em Atenção Basica em Saúde da Família da Universidade Federal de Minas Gerais. Belo Horizonte, 2010.

LIMA, M.; DIMENSTEIN, M. O apoio matricial em saúde mental: uma ferramenta apoiadora da atenção à crise. Interface - Comunicação, Saúde, Educação [online], v. 20, n.58, p. 625-635, 2016. Disponível em: <https://doi.org/10.1590/1807$\underline{57622015.0389}>$. Acesso em 06 de setembro de 2021.

MINÓIA, N. P.; MINOZZO, F. Acolhimento em Saúde Mental: Operando Mudanças na Atenção Primária à Saúde. PSICOLOGIA: CIÊNCIA E PROFISSÃO, 2015. 
NASI, C.; SCHNEIDER, J. F. O Centro de Atenção Psicossocial no cotidiano dos seus usuários. O MUNDO DA SAÚDE, São Paulo: 2011;35(2):162-168.

PINTO, D. M.; et al. PROJETO TERAPÊUTICO SINGULAR NA PRODUÇÃO DO CUIDADO INTEGRAL: UMA CONSTRUÇÃO COLETIVA. Texto Contexto Enferm, Florianópolis, 2011 Jul-Set; 20(3): 493-302.

SAMPAIO, M. L.; JÚNIOR, J P. B. Rede de Atenção Psicossocial: avaliação da estrutura e do processo de articulação do cuidado em saúde mental. Caderno de Saúde Pública, 2021.

SILVA JÚNIOR, A.G.; MASCARENHAS, M. T.M. Avaliação da Atenção Básica em Saúde sob a ótica da Integralidade: aspectos conceituais e metodológicos. In: PINHEIRO R.; MATTOS, R. A. de (org). Cuidado: as fronteiras da Integralidade. $3^{a}$ Ed. Rio de Janeiro: UERJ, IMS: ABRASCO, 2006. p. 241-58. 